\title{
Effect of alterations in the arterial carbon dioxide tension on the blood flow through the cerebral cortex at normal and low arterial blood pressures
}

\author{
A. MURRAY HARPER AND H. I. GLASS \\ From the University Department of Surgery, Glasgow Royal Infirmary, and the Wellcome Laboratory, \\ University of Glasgow
}

It is well known that the cerebral blood flow alters in response to changes in the arterial carbon dioxide tension. However, it is not yet clear whether there are upper and lower limits of $\mathrm{Pa}_{\mathrm{CO}}$, beyond which the cerebral vessels do not react. In addition, there have been no reports on the response of cerebral blood flow to alterations in $\mathrm{Pa}_{\mathrm{CO}}$ in hypotensive states.

The recent development by Lassen and Ingvar (1961, 1962) of a rapid, easily repeatable, and relatively untraumatic method of estimating the blood flow through the cerebral cortex has enabled us to make multiple estimations of blood flow in lightly anaesthetized dogs at varying tensions of arterial carbon dioxide and varying arterial blood pressures.

\section{METHOD}

Three hundred and two measurements of blood flow through the cerebral cortex were made on 41 unselected mongrel dogs. The animals were anaesthetized with thiopentone. A cuffed endotracheal tube was inserted and connected to a Starling respiratory pump, through which a 4:1 mixture of $\mathrm{N}_{2} \mathrm{O}$ and oxygen was delivered in open circuit. Suxamethonium chloride was administered at intervals. Repeated small doses of thiopentone were given during the actual operation. A cannula was inserted into the femoral artery and connected to a damped mercury manometer for the measurement of the systemic blood pressure. This cannula was also used for the withdrawal of arterial blood samples.

The thyroid branch of the common carotid artery was cannulated centripetally, the distal end being tied. The temporal muscle was excised and a trephine hole made over the parietal bone. A cruciate incision was made in the dura and the exposed brain cortex was covered with a plastic membrane (Melinex) $6 \mu$ in thickness. A thin lead shield was placed over the surrounding dura and bone, leaving exposed only the area of cortex covered by the membrane. An end window Geiger counter, mounted $1 \mathrm{~mm}$. above the exposed cortex, was connected to a ratemeter and a direct writing recorder. After the operation was completed, thiopentone administration was dis- continued and the preparation remained undisturbed for one hour before the first measurements of blood flow were made. Plasma substitute (Dextran), saturated with 85 Krypton, was injected, rapidly at first and then more slowly, into the carotid artery over two to three minutes. The blood flow through the brain cortex was calculated from the half-life of the initial slope of a semilogarithmic plot of the clearance curve using the formula of Lassen and Ingvar (1961, 1962). After each measurement of blood flow, blood samples were taken from the femoral artery for the measurement of $\mathrm{Pa}_{\mathrm{co}_{2}}$ and $p \mathrm{H}$ on the micro-Astrup apparatus. Arterial oxyhaemoglobin saturation was measured at intervals on a Kipp haemoreflector. Pharyngeal temperatures were measured with a mercury thermometer.

The experiments were divided into three groups.

GROUP I: NORMOTENSIVE The $\mathrm{Pa}_{\mathrm{co}_{2}}$ was gradually raised in 10 dogs by adding increasing quantities of carbon dioxide to the anaesthetic mixture, and lowered in nine dogs by increasing the volume delivered by the respiratory pump.

GROUP II: HYPOTENSIVE The mean arterial blood pressure was maintained at $100 \mathrm{~mm} . \mathrm{Hg}$ by bleeding the animals into a reservoir flask held at this pressure. The $\mathrm{Pa}_{\text {co, }}$ was raised in seven dogs and lowered in five dogs.

GROUP III: HYPOTENSIVE The mean arterial blood pressure was maintained at $50 \mathrm{~mm} . \mathrm{Hg}$. The $\mathrm{Pa}_{\mathrm{Co}_{2}}$ was raised in five dogs and lowered in five dogs.

\section{RESULTS}

GROUP I The effect of hypercapnia and hypocapnia on the blood flow through the cerebral cortex in normotensive dogs (mean initial blood pressure $150 \mathrm{~mm} . \mathrm{Hg}$ ) is shown in Figure 1. In each experiment there was a marked rise in blood flow as the $\mathbf{P a}_{\mathrm{co}}$ increased and a fall in blood flow as the $\mathrm{Pa}_{\mathrm{CO}_{2}}$. decreased. The rise in $\mathrm{Pa}_{\mathrm{CO}_{2}}$ was accompanied by a fall in $p \mathrm{H}$ and vice versa.

As there was considerable variation in the initial control values for each experiment, the blood flow was plotted against the $\mathrm{Pa}_{\mathrm{CO}}$ individually for each 


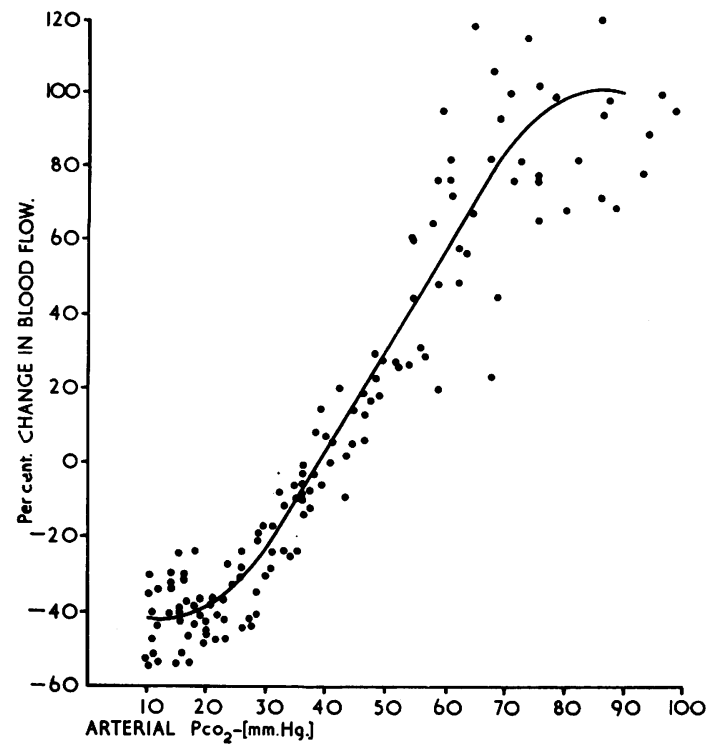

FIG. 1. The effect of alterations in $\mathrm{Pa}_{\mathrm{CO}}$ in normotensive animals on the cortical blood flow. Zero reference line for blood flow is at $\mathrm{Pa}_{\mathrm{CO}_{2}}$ of $40 \mathrm{~mm} . \mathrm{Hg}$. (Tables giving the data from which this and subsequent figures were constructed will be sent by the authors on request.)

dog. A line giving the best fit for each experiment was drawn by hand and each dog's flow results expressed as a percentage of its blood flow at an arterial carbon dioxide tension of $40 \mathrm{~mm} . \mathrm{Hg}$ as estimated from the individual graph. This enabled the results in each experiment to be expressed as a percentage change in blood flow from that occurring at a $\mathrm{Pa}_{\mathrm{CO}_{2}}$ of $40 \mathrm{~mm} . \mathrm{Hg}$. The points from all the experiments in this group have been plotted in Figure 1. A Deuce digital computer was used to fit a polynomial curve. A cubic curve was found to give the best fit. From Fig. 1 it can be seen that raising the $\mathrm{Pa}_{\mathrm{CO}_{2}}$ from 40 to $80 \mathrm{~mm}$. Hg caused approximately a $100 \%$ increase in blood flow. Lowering the $\mathrm{Pa}_{\mathrm{CO}_{2}}$ from 49 to $20 \mathrm{~mm} . \mathrm{Hg}$ caused a $40 \%$ decrease in blood flow. Reducing of the $\mathrm{Pa}_{\mathrm{CO}_{2}}$ below $20 \mathrm{~mm}$. $\mathrm{Hg}$ caused no further decrease in blood flow.

GROUP II In the experiments in this group, the mean arterial blood pressure was held at $100 \mathrm{~mm} . \mathrm{Hg}$. The response of the blood flow to hypercapnia and hypocapnia is shown in Figure 2. The change in blood flow on altering the $\mathrm{Pa}_{\mathrm{CO}_{2}}$ is similar to, but less pronounced than, in group I. It can be seen from Fig. 2 that the percentage increase in blood flow when the $\mathrm{Pa}_{\mathrm{CO}_{2}}$ is raised from 40 to $80 \mathrm{~mm} . \mathrm{Hg}$ is only $50 \%$ (compared with $100 \%$ increase in group 1 ). Similarly, the reduction in flow when the $\mathrm{Pa}_{\mathrm{CO}_{2}}$

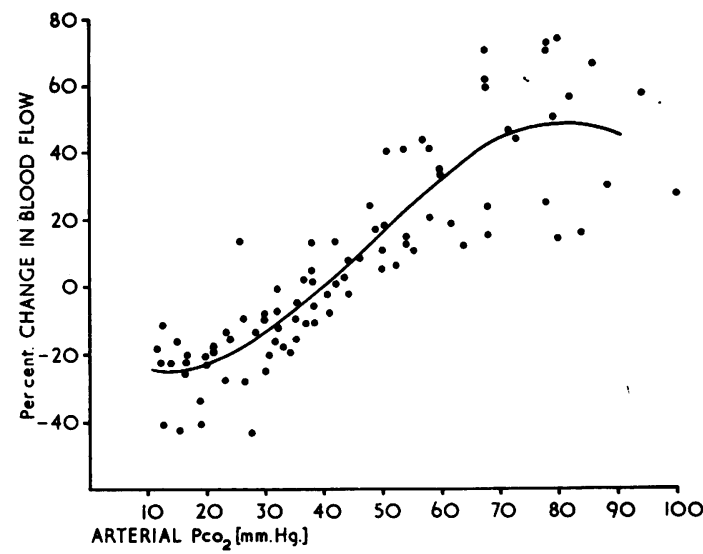

Fig. 2. The effect of alterations in $\mathrm{Pa}_{\mathrm{CO}_{2}}$ in hypotensive animals (mean arterial blood pressure $100 \mathrm{~mm} . \mathrm{Hg}$ ) on the cortical blood flow. Zero reference line for blood flow is at $\mathrm{Pa}_{\mathrm{CO}_{2}}$ of $40 \mathrm{~mm} . \mathrm{Hg}$.

was lowered from 40 to $20 \mathrm{~mm} . \mathrm{Hg}$ was only $25 \%$ (compared with a $40 \%$ decrease in group 1).

GROUP III In this group the mean arterial blooo pressure was held at approximately $50 \mathrm{~mm} . \mathrm{Hg}_{\mathbb{1}}$ The effects of hypercapnia and hypocapnia on the्ष cerebral blood flow are shown in Figure 3. It is evident that at this level of hypotension, neithes raising not lowering the $\mathrm{Pa}_{\mathrm{CO}}$, had any significang $\stackrel{0}{\circ}$ effect on the blood flow.

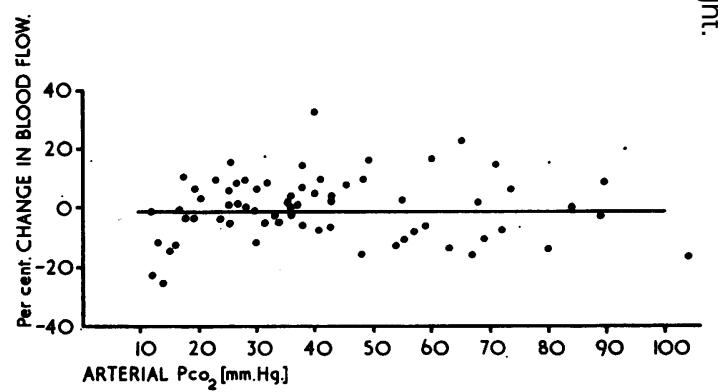

FIG. 3. The effect of alterations in $\mathrm{Pa}_{\mathrm{CO}_{2}}$ in hypotensive animals (mean arterial blood pressure $50 \mathrm{~mm} . \mathrm{Hg}$.) on the cortical blood flow. Zero reference line for blood flow is at $\mathrm{Pa}_{\mathrm{CO}_{2}}$ of $40 \mathrm{~mm} . \mathrm{Hg}$.

\section{DISCUSSION}

Before assessing the results of these experiments, the importance of careful surgical technique, light anaesthesia, and control of respiration must be emphasized. Great care was taken to ensure that the brain was not injured in any way during surgery. If this happened, or if there was any persistent con- 
tamination of the surface of the cortex by blood, the experiment was abandoned and no measurements were made. As an additional precaution the first measurement of blood flow was not made until one hour after the operation had been completed.

Following surgery, only nitrous oxide anaesthesia was used. This gave a steady, active pattern on the E.E.G. In early experiments under barbiturate anaesthesia, we were unable to get consistent results, presumably due to too deep anaesthesia or to variations in depth of anaesthesia. The effect of nitrous oxide on cerebral blood flow has not been previously determined, but it was assumed to be less depressant to cerebral blood flow and metabolism than barbiturate anaesthesia.

Throughout these experiments great pains were taken to ensure steady state conditions and careful control of the physiological variables considered of importance in the control of cerebral circulation. This was achieved by meticulous control of ventilation, frequent monitoring of $\mathrm{Pa}_{\mathrm{CO}}$, and arterial oxygen saturation, and maintenance of body temperature at approximately $38^{\circ} \mathrm{C}$. Although changes in blood $p \mathrm{H}$ were observed in most experiments, this was not considered important, as a recent report has shown that under steady state conditions with a constant $\mathrm{Pa}_{\mathrm{CO}_{2}}$, changes in $p \mathrm{H}$ of the arterial blood do not significantly alter cerebral blood flow (Harper and Bell, 1963). We feel, therefore, that the changes in blood flow noted in these experiments reflect the induced alterations in $\mathrm{Pa}_{\mathrm{CO}_{2}}$ and blood pressure, and are not due to the influence of extraneous factors such as hypoxia or variations in depth of anaesthesia.

In the experiments in which the $\mathrm{Pa}_{\mathrm{CO}_{2}}$ was altered in normotensive animals, the well known effects of cerebral vasodilatation during hypercapnia and vasoconstriction during hypocapnia were found. From Fig. 1 there appears to be a lower limit beyond which the cerebral vessels could not constrict. Blood flow did not decrease further below a $\mathrm{Pa}_{\mathrm{CO}_{2}}$ of $20 \mathrm{~mm} . \mathrm{Hg}$. This finding is in agreement with the work of Noell and Schneider (1944), who reported no further decreases in cerebral blood flow (as calculated from the A-V oxygen difference) below a $\mathrm{Pa}_{\mathrm{CO}_{2}}$ of $20 \mathrm{~mm} . \mathrm{Hg}$. They suggested that the anoxic stimulus of low tissue oxygen tension was sufficient to counteract any further vasoconstrictive effect of hypocapnia.

From the shape of the curve in Fig. 1, it could be postulated that there was no further increase in blood flow beyond a $\mathrm{Pa}_{\mathrm{CO}_{2}}$ of $80 \mathrm{~mm} . \mathrm{Hg}$. This is more evident in Fig. 2, where levelling out was definite at a $\mathrm{Pa}_{\mathrm{CO}_{2}}$ of $70 \mathrm{~mm} . \mathrm{Hg}$. This suggests that in hypercapnia the cerebral vessels eventually reach maximum dilatation.
Patterson, Heyman, Battey, and Ferguson (1955) have suggested that the response of the cerebral blood vessels to hypercapnia is a threshold phenomenon and only occurs when the $\mathrm{Pa}_{\mathrm{CO}}$, has risen by more than $4 \mathrm{~mm} . \mathrm{Hg}$. In our experiments the collected results from all dogs show a steady rise in blood flow with increased $\mathrm{Pa}_{\mathrm{CO}_{2}}$. As the coefficient of variation of repeated estimations under constant experimental conditions using the 85 Krypton clearance technique (Ingvar and Lassen, 1962; Harper, Glass, and Glover, 1961) is $8-10 \%$, changes in blood flow of less than this figure would be difficult to detect. It would be interesting to know the coefficient of variation of repeated estimations with the $\mathrm{N}_{2} \mathrm{O}$ technique (Kety and Schmidt, 1945) used by Patterson and his colleagues (1955). If it was of the same order fairly small increases in blood flow could be missed.

It has been suggested (Lassen, 1959) that the teleological implication of the cerebral vasodilatation produced by hypercapnia is to maintain a constant cerebral tissue tissue $\mathrm{P}_{\mathrm{CO}_{2}}$ and that any increase in tissue $\mathrm{P}_{\mathrm{CO}_{2}}$ (due to increased metabolism) will result in increased cerebral perfusion, and the disposal of the excess $\mathrm{CO}_{2}$. However, in hypotensive conditions, this regulation of cerebral blood flow in response to changes in $\mathrm{Pa}_{\mathrm{CO}_{2}}$ is impaired.

In Fig. 2, where the mean arterial blood pressure was reduced to and maintained at $100 \mathrm{~mm} . \mathrm{Hg}$, the increase in blood flow on raising the $\mathrm{Pa}_{\mathrm{CO}_{2}}$ from 40 to $80 \mathrm{~mm} . \mathrm{Hg}$ was only $50 \%$ compared with the $100 \%$ increase in the normotensive dogs. Similarly, there was considerably less reduction in flow with hypocapnia. This is even more strikingly shown in Fig. 3, where, at a mean arterial blood pressure of $50 \mathrm{~mm} . \mathrm{Hg}$, no change in flow occurred during either hypercapnia or hypocapnia. It has been shown (Forbes, Nason, and Wortman, 1937; Fog, 1938; Carlyle and Grayson, 1955; Rapela, Machowicz, and Freeman, 1963; Harper, 1965; Haggendal and Johansson, 1965) that the cerebral blood vessels are able to dilate to compensate for a fall in arterial blood pressure, and we would postulate that in severe hypotensive states the cerebral vessels, being already maximally dilated, are unable to dilate further in response to increased $\mathrm{Pa}_{\mathrm{CO}_{2}}$. The failure of the cerebral vessels to constrict when the $\mathrm{Pa}_{\mathrm{CO}_{2}}$ is lowered could indicate that in severe hypotension the maintenance of cerebral perfusion takes precedence over the maintenance of a normal tissue $\mathrm{PcO}_{2}$. This 'over-ride' mechanism could be mediated through the tissue oxygen tension, which is presumably low due to the inadequate blood flow, and could counteract the vasoconstrictive effect of hypocapnia.

Finally, the clinical application of the finding 
reported in this paper would be that there is no advantage in the administration of $\mathrm{CO}_{2}$ in an attempt to restore cerebral blood flow in severe shock. On the contrary, such an action might raise the cerebral tissue $\mathbf{P}_{\mathrm{CO}_{3}}$ to dangerously high levels.

\section{SUMMARY}

Measurements of blood flow through the exposed cerebral cortex were made in lightly anaesthetized dogs, using the ${ }^{85}$ Krypton clearance method of Lassen and Ingvar (1961). In normotensive animals, hypercapnia produced a marked increase, and hypocapnia a decrease, in blood flow. However, in hypotensive animals this effect was reduced or absent.

This work was supported by a grant from the Medical Research Council. One of us (A.M.H.) is Wellcome Senior Research Fellow in Clinical Science.

We are extremely grateful to Professor W. A. Mackey for his continued encouragement and support. We must thank Dr. N. A. Lassen for his helpful criticism and advice.

\section{REFERENCES}

Cartyle, A., and Grayson, J. (1955). Blood pressure and the regulation of brain blood flow. J. Physiol. (Lond.), 127, 15P-16P.
Fog, M. (1938). The relationship between the blood pressure and the tonic regulation of the pial arteries. J. Neurol. Psychiat., 1, 187-197.

Forbes, H. S., Nason, G. I., and Wortman, R. C. (1937). Cerebral circulation: vasodilation in pia following stimulation of the vagus, aortic and carotid sinus nerves. Arch. Neurol. Psychiat., (Chic). 37, 334-350.

Haggendal, E., and Johansson, B. (1965). Effects of arterial carbon dioxide tension and oxygen saturation on cerebral blood flow autoregulation in dogs. Acta physiol. scand., 66, suppl. 258, pp. 27-53.

Harper, A. M. (1965). Physiology of cerebral bloodflow. Brit. J. Anaesth., 37, 225.

-, and Bell, R. A. (1963). The effect of metabolic acidosis and alkalosis on the blood flow through the cerebral cortex. J. Neurol. Neurosurg. Psychiat., 26, 341-344.

_, Glass, H. I., and Glover, M. M. (1961). Measurement of blood flow in the cerebral cortex of dogs, by the clearance of Krypton $^{86}$. Scot. med. J., 6, 12-17.

Ingvar, D. H., and Lassen, N. A. (1962). Regional blood flow of the cerebral cortex determined by Krypton ${ }^{85}$. Acta physiol. scand., 54, 325-338.

Kety, S. S., and Schmidt, C. F. (1945). The determination of cerebral blood flow in man by the use of nitrous oxide in low concentrations. Amer. J. Physiol., 143, 53-66.

Lassen, N. A. (1959). Cerebral blood flow and oxygen consumption in man. Physiol. Rev., 39, 183-238.

-, and Ingvar, D. H. (1961). Blood flow of the cerebral cortex determined by radioactive Krypton ${ }^{85}$. Experientia (Basel), 17, 42-43.

Noell, W. and Schneider, M. (1944). Über die Durchblutung und die Sauerstoffversorgung des Gehirns. IV. Die Rolle der Kohlensäure. Pflügers Arch. ges. Physiol., 247, 514-527.

Patterson, J. L., Heyman, A., Battey, L. L., and Ferguson, R. W. (1955). Threshold of response of the cerebral vessels of man toO increase in blood carbon dioxide. J. clin. Invest., 24, 1857-1864.

Rapela, C. E., Machowicz, P. P.. and Freeman, G. (1963). Effect of $\mathrm{CO}_{2}$ on autoregulation of cerebral blood flow. Fed. Proc., 22, 344. 